\title{
Prevalence of Chronic Illnesses among Medical Students at King Faisal University (KFU) and their Impact on Academic Performance
}

\author{
Ashraf Ahmed Zaher ${ }^{1}$, Sayed Ibrahim Ali ${ }^{2}$, Mohammed Ahmed Alalwan ${ }^{3}$, Ahmad Hussien Buzaid ${ }^{3}$, \\ Hassan Wasel Aldandan ${ }^{3}$ \\ ${ }^{1}$ Neurology Department, King Faisal University, Saudi Arabia -Mansoura University, Egypt \\ (Main Author) \\ ${ }^{2}$ Family Medicine Department, King Faisal University, Saudi Arabia \\ ${ }^{3}$ Medical Intern, King Faisal University, Saudi Arabia
}

\begin{abstract}
Background: Chronic diseases have a range of potential impacts on a person's individual circumstances, including quality of life and broader social and economic effects. Objective and Purpose: The aim of this study was to determine the prevalence and impact of chronic illness on the academic performance among undergraduate medical students at KFU. Methods: A cross sectional study was conducted at college of medicine, KFU, KSA, and was assessed by semi structured questionnaire based on National Health Interview Survey, Health Care Experiences (CSHCN Screener) and School Interference (VAS and PedsQL School Subscale). a variety of measures assessing academic attendance, performance, sociodemographic characteristics, health related habits, physical activity and diseases listed by national health interview survey. Results: A total Of 197 students were assessed, males were 52.28 \%(103/197)and females $47.7 \%(94 / 197)$ with a mean age $=22.7 \pm 1.68$. Incidence of absenteeism at school: $1-3$ times $(39.1 \%$, N77), 4-6 times $(23.4 \%$, N46) More than 7 times $(13.6 \%$, N27), never missed classes $(23.9 \%$, N47) $29.9 \%$ were having chronic diseases around (22.8\%, N45) missing classes due to oversleeping, around (10.2\%, N20) due appointment, and due chronic diseases(N18, 9.1\%), Students who were missing classes due other reasons $(\mathrm{N25}, 12.5 \%)$.Prevalence of chronic diseases was slightly higher in males $(15.2 \%$ vs $14.72 \%)$ than females. The most prevalent condition was irritable bowel syndrome, females (12.8\%), male (6.8\%, ), nutritional anemia: females (3.9\%), and males (10.6\%, ), sickle cell anemia: males (9.6\%, ), females(1\%), repeated diarrhea: females (2.10\%), males(1\%), food allergy: females(5.30\%) and males were (1\%). No statistically significant difference between students with chronic illnesses and those without as regard grade point average (GPA): p-value=0.738. Conclusion: Chronic illnesses among medical students have no significant impact on their academic performance.
\end{abstract}

Keywords: Chronic diseases, chronic illness, academic performance

\section{Introduction}

Chronic illnesses are a condition which last for a considerable period of time or has sequelae which persists for a substantial period and/or persists for more than 3 months in a year or necessitates a period of continuous hospitalizations for more than a month. They are the primary cause of death in Saudi Arabia (69\%, N67000) (1).

Young adults specifically, are potentially faced with the challenge of attending college. The personality of adolescent continues to develop until twenties (2), The transition to college is a major life adjustment, and is a stressful event for anyone. Moving apart from home, increase independency, making new friends, and possibly difficulty in managing time. all are different aspects of the college transition, and are important for good adjustment. Some handle this transition with negligible difficulty, while others are not flexible (3). Furthermore, Improper coping with stress may lead to self-destructive and aggressive behaviors as dark as suicide(4).

Adolescence entering colleges with chronic medical conditions have additional challenges in comparison to their healthy peers. There is no standardized protocol for accommodating students with chronic illness (5). As a result, students with a chronic illness must seek out any services they need on their own. Consistent with research on children and 16 chronic illnesses, studies involving college students with asthma and allergies have shown an association of illnesses severity with mental health problems and poor academic performance (6). Students with sickle cell anemia needs special educational services and demonstrate more missed classes when compared to their healthy peers (7).in addition, students with chronic diseases are less probable to graduate from college (8).

Generally new research is important to demonstrate if there is association between chronic non communicable diseases and academic difficulties among college students.

\section{Methods}

A cross sectional study was conducted among 197 undergraduates and interns medical students at King Faisal University in Al-Ahsa city, Saudi Arabia The sample was split between females $(\mathrm{N}=94,47 \%)$ and males $(\mathrm{N}=103$, $53 \%$ ) A pre-tested, semi-structured questionnaire based on Health Care Experiences (CSHCN Screener), National Health Interview Survey, School And Interference (VAS and PedsQL School Subscale) was used to collect information on Age demographics, lifestyle, self-rated health status, and list of reported morbidities. Smoking status was categorized as either current smoker (daily and occasional smoking) or non-smoker (individuals who had 


\section{International Journal of Science and Research (IJSR) \\ ISSN (Online): 2319-7064}

Index Copernicus Value (2013): 6.14 | Impact Factor (2015): 6.391

never smoked and former smokers). Consumption of alcoholic beverages, Data on the weekly frequency and duration of physical activity performed in the subjects' leisure time and walking as a means of locomotion were also collected. According to criteria (9), the variables measuring leisure-time physical activity and walking were categorized as either active or sedentary. Chi-square tests were conducted to check for any differences in demographics between the groups.

Statistical analysis: was performed using SPSS program $21^{\text {st }}$ version, descriptive analysis was presented in form of tables and graphs. The frequencies and percentages of Sociodemographic characteristics and college year in study participants were calculated. $\mathrm{P}$-value considered to be significant if less than 0.05 , Chi-square tests were conducted to check for any differences in demographics between the groups.

\section{Results}

Analyses focused only on students who were full-time students. Students who reported enrolling in less than 4 classes in the previous semester were removed in addition; participants with missing data for any item were removed from all analyses. This resulted in a final sample of 197 participants, males 52.28\%(103/197), females 47.7\%(94/197) with Mean age: $22.7 \pm 1.68$ and identified according to residency as rural (24) $12.2 \%$ and urban (173) $87.8 \%$ and according to marital status: married $(16.8 \%, \mathrm{~N}$ $33)$, single $(82.7 \%, \mathrm{~N} 182)$ and divorced $(0.5 \%, \mathrm{~N} 1)$ and p- value: 0.011 in favor of male single. And they were identified by college year interns $(21.3 \%, N 42), 6^{\text {th }}$ year $(23.4 \%, \mathrm{~N} 46), 5^{\text {th }}$ year(19.8\%, N39), $4^{\text {th }}$ year(18.3\%, N36 ), $3^{\text {rd }}$ year $(14.7 \%, \mathrm{~N} 29), 2^{\text {nd }}$ year $(1.5 \%, \mathrm{~N} 3), 1^{\text {st }}(1 \%, \mathrm{~N} 2)$ and $\mathrm{p}$-value $=0.001$ in favor of $6^{\text {th }}$ year students. All of them answered no when it came to alcohol consumption. Playing sports and physical activity $\mathrm{P}$-value $=0.02$ in favor of males, smoking p-value $=0.0001$ in favor of male. Family history of chronic diseases p-value $=0.02$ in favor of female. As mentioned in (table 1).

Around $15 \%$ of the sample responded "yes" to the questions "During the Last semester did any of the conditions cause you to miss any time from School?" $(15 \%, \mathrm{n}=30)$ which is far from the study conducted by (Casey Lawless Syracuse University) which mentioned that around half of the respondents missing classes due the chronic illnesses, around $(22.8 \%, \mathrm{~N} 45)$ missing classes due to oversleeping, and around $(10.2 \%$, N20) due appointment. See (table 2). Students who were missing classes due other reasons (N25, 12.5\%) (table3).

Incidence of absenteeism school: 1-3 times (39.1\%, N77), 4-6 times $(23.4 \%, \mathrm{~N} 46)$ More than 7 times $(13.6 \%, \mathrm{~N} 27)$, never missed classes $(23.9 \%, \mathrm{~N} 47)$

The total percentage of participants identified as having a chronic medical condition was $(29.9 \% n=59)$. Therefore, the number of participants identified as "healthy, " or not possessing a significant chronic medical condition, was $70.1 \%(n 138)$.
Analysis also indicated a difference between having a chronic medical condition and gender. In which female with chronic condition were $(14.72 \%, \mathrm{~N} 29)$, and male (15.2\%, N30). (Figure 1)

Within the chronic illness group, there was a wide variety of conditions reported. The most prevalent condition was irritable bowel syndrome, which occurred in $9.6 \%$ of the entire sample $(n=19)$. Female $(12.8 \%, \mathrm{~N} 12$ out of 94$)$, male $(6.8 \%, \mathrm{~N} 7$ out of 103$)$, p-value $=0.033$ in favor of irritable bowel syndrome in females (figure1).

Other conditions that occurred in greater than $5 \%$ of the sample included the Following: anemia due other reasons in which occurred in $7.1 \%$ of entire sample in which females $(3.9 \%, \mathrm{~N} 494)$, and males $(10.6 \%, \mathrm{~N} 10$ out of 103), sickle cell anemia: the prevalence in total sample was $5.1 \%$ in which males $(9.6 \%$, N9 out of 103), and females $(1 \%$, N1 put of 94), repeated diarrhea: females $(2.10 \%)$, males(1\%), food allergy: females(5.30\%) and males were(1\%). (Figure 1).

GPA: (4-5), (52.3\%, N45)in which (53.2\%)without chronic diseases VS(51.3\%)with chronic diseases, GPA: (3-4), (30.2\%, N26)in which (29.8\%) without chronic diseases VS (30.8\%) with chronic diseases, GPA: (2-3), $(16.3 \%$, N14)in which (17\%)without chronic diseases VS(15.4\%) with chronic diseases, GPA: (1-2), (2.6\%, $\mathrm{N} 1)$ in which he was free of chronic diseases.(figure2)

There is no significant difference between students affected by a chronic medical conditions and those who are not $=p=0.738$ according to GPA and there is no difference between males and females as regard GPA: $p$ value: 0.064 (Figure 2 ).

Food allergy: prevalence in total sample was $3 \%$ in which female $(5.3 \%$, N5 out of 94$)$ and males $(1 \%, \mathrm{~N} 1$ out of $103)$, peptic ulcer: prevalence in total sample was $2.5 \%$ in which females $(3.9 \%$, N4 out of 94$)$, and male $(1 \%, \mathrm{~N} 1$ out of 103) Repeated diarrhea: prevalence of total sample was $1.5 \%$ in which females $(2.1 \%, \mathrm{~N} 2$ out of 94$)$ and males $(1 \%, \mathrm{~N} 1$ out of 103$)$, jaundice: prevalence in total sample was $0.5 \%(1 \%, \mathrm{n}=1$ out of 103$)$ in males, thalassemia: prevalence in total sample was $0.5 \%(1 \%, \mathrm{~N} 1$ out of 94) Around $15 \%$ of the sample responded as mentioned in( figure 1)"yes" to the questions "During the Last semester did any of the conditions cause you to miss any time from School?" (15\%, $n=30)$, around (22.8\%, N45) missing classes due to oversleeping, and around (10.2\%, N20) due appointment. The average amount of classes in the past semester that were reported to have been missed due to a other reasons than the listed in table $5(53.8 \%$, N106). In response to the stem "When this condition did bother you, you were bothered" 18 of those with chronic Medical conditions reported it bothering them "a great deal" $(9.1 \%, \mathrm{~N} 18)$ In the domain of academic performance, as addressed grade point average that students who answered yes to have chronic illnesses showed: GPA $(4-5)=(53.2 \%$, N25) GPA $(3-4)=(29.8 \%$, N14), GPA $(2-3)=(17 \%$, N8), GPA $(1-2)=(0 \%$, N0). Students who denied having chronic illnesses: GPA (4-5) $=(51.3 \%, \mathrm{~N} 20)$, GPA $(3-4)=(30.8 \%, \mathrm{~N} 12)$, GPA $(2-3)=$ 


\section{International Journal of Science and Research (IJSR) \\ ISSN (Online): 2319-7064}

Index Copernicus Value (2013): 6.14 | Impact Factor (2015): 6.391

$(15.4 \%$, N6), GPA $(1-2)=(0 \%$, N0). Students who denied having chronic illnesses: GPA $(4-5)=(51.3 \%, \mathrm{~N} 20), \mathrm{GPA}$ $(3-4)=(30.8 \%, N 12)$, GPA $(2-3)=(15.4 \%$, N6), GPA $(1-$ 2) $=2 . \%$

$\%+\mathrm{Lp} \mathrm{L5}$ !.\%

@ O4/-\&

$2 . \%$

$\%+\mathrm{Lp} \mathrm{L} 5 ! . \%$

@ $04 /-$

\section{Limitations}

This study was not without limitations. The sample was not truly random, as participants were recruited in order to fulfill class requirements. The size of the sample was relatively small and less representative and participants were all drawn from one University and one college in $\mathrm{Al}$ Ahsa, Saudi Arabia. Which may limit our generalizability of the results, and future studies should include a broader approach to participant recruitment. Another limitation is that the sample was primarily composed of senior students, who are last years. Adjusting to college life. Grade point averages and class attendances could vary throughout the college years. In addition, data were gathered via selfreported questionnaire, which could lead to recall bias, especially in disclosure of grade point averages. Furthermore, remembering class schedules and estimating the number of classes missed, semester may have been difficult for some participants to estimate. The way in which chronic illness was defined also could have affected the results.

Furthermore, age of onset was not taken into account. A previous study found that the longer someone has a chronic medical condition, the less interference it has with school and activities (10). Another aspect is the conservative Saudi community which difficult to students admits certain habits as alcohol consumption, also psychological status of students was not asked properly.

\section{Discussion}

The chronic illnesses mentioned in this study give us a hint about the most common conditions among medical students. This sample has total chronic condition prevalence of $29.9 \%$ which is not much far from $22 \%$ of similar research (11). The most prevalent condition was irritable bowel syndrome $9.6 \%$ in entire sample which was far from the prevalence of medical students in Pakistan which was $26 \%$ (12). the second most prevalent disease was anemia in which prevalence in total sample was $7.1 \%$ which is far from similar study in which the prevalence was $(30.20 \%)(13)$, also sickle cell anemia and peptic ulcers and repeated diarrhea were common in this study. Other conditions that are common in other studies like HTN, DM, arthritis, cardiovascular diseases, and cancer that are common according to previous study (14) were not present on this study.

Around $15 \%$ of the sample responded "yes" to the questions "During the Last semester did any of the conditions cause you to miss any time from School?" $(15 \%, \mathrm{n}=30)$ which is far from the study conducted by lawless casey which mentioned that around half of the respondents missing classes due the chronic illnesses (11), around $(22.8 \%, \mathrm{~N} 45)$ missing classes due to oversleeping, and around $(10.2 \%, \mathrm{~N} 20)$ due appointment, Students who were missing classes due other reasons $(\mathrm{N} 25,12.5 \%)$ the occurrence of absenteeism were not accidental and students freely choose to be absent by multiple factors including lack of self-discipline, peer pressure, lack of study skills or time management and extracurricular activities and other study (15-16) link between absenteeism and low motivation, poor teaching strategies, lack of interest, being over social, part-time jobs, ill health, lack of sleep, and number of times being missing school: 1-3 times (39.1\%, N77), 4-6 times $(23.4 \%$, N46) More than 7 times $(13.6 \%, \mathrm{~N} 27)$, never missed classes $(23.9 \%$, N47) (table 3) Which is not far from similar study that showed $43.7 \%$ had missed three or more lectures and $14.1 \%(95 \% \mathrm{CI}=12.2-16.2)$ missed more than 8 lectures in the preceding semester (17).

Playing sport and physical activity P-value $=0.02$ in favor of males and studies showed that physical inactivity is another risk in which people who are physically inactive are two times more likely to exhibit depression and anxiety (18). a low physical activity is one of the major causes of chronic diseases like HTN, DM, and obesity (1). Most of health college students in Saudi Arabia were physically inactive which might indicate higher risk of chronic conditions (19).

Smoking p-value $=0.0001$ in favor of male students. According to study conducted among college students in Greece (20) that A good knowledge of bad effects showed a strong association with nonsmokers. And nonmedical students revealed higher possibility to be a smoker, knowing bad effects of smoking among medical students was not a significant factor against smoking compared with nonmedical students.

It is estimated that the population of people with chronic conditions will increase steadily in that next two decades (21). As the number of people affected by chronic illness increases, the associated problems will only become worse. This will result in dramatically larger numbers of young adults entering College with chronic diseases, which, according to results of previous studies, students will have significant mental health problems. Previous studies also showed that patients with chronic illnesses suffer psychological stressors due to requirement related to management of their physical health problems (22). Therefore, these affected college students may benefit from psychosocial support in addition to medical care. This is especially true in case of medical students in which they were more likely to seek medical support (13). It is vital that people of this age get help because of different coping and life style that health education intervention was important to achieve significant changes in life style (23). Previous researches reported an association between chronic medical conditions and mood disorders. The stress-filled college environment is especially hard on these students, as chronic disease is already associated with a risk of depression and anxiety (24-25). 


\section{International Journal of Science and Research (IJSR) \\ ISSN (Online): 2319-7064}

Index Copernicus Value (2013): 6.14 | Impact Factor (2015): 6.391

An additional challenge for all college students in particular living away from home is the dietary habits in which they develop unhealthy eating habits towards globalized behaviors (26-27). Undoubtedly, having depression will continue to interfere with the friendmaking process in college, leading to social isolation. The college experience is notorious for being a time of high risk behavior and poor decision making in the general population. Several studies have found that adolescents with chronic disorders "engage in experimental behavior and place themselves in risky situations as often as or even more often than their peers" (28). Also in another research Young adults with hidden disabilities have a much higher rate of drug and alcohol use than their peers without these conditions (29). Rates that will most likely continue in college if not addressed. Without intervention, the mental health problems experienced by these students may extend not only through college, but into the future (30). Therefore, depression must be caught as early as possible in order to prevent unnecessary physical decline.

The results of this research did not support for the hypothesis we mentioned before. Academic performance would vary whether the student have a chronic illness or not. Participants with chronic illness report the same frequency of missed class as did their healthy peers. Affected students did not demonstrate poorer academic performance. Additionally, both groups had comparable amounts of perceived difficulties in academic performance.

In conclusion, chronic illnesses have no significant effect on academic performance among medical students, further studies with larger numbers needed, psychological status and psychiatric illnesses scales should be included to assess the effects of chronic conditions.

Table 1

\begin{tabular}{|c|c|c|c|}
\hline \multicolumn{4}{|c|}{ Sociodemographic characteristics and college year in study } \\
participants \\
\hline \multirow{2}{*}{ Subject } & Category & Numbers & Percentage \\
\hline \multirow{4}{*}{ Gender } & Male & 103 & $52.3 \%$ \\
\cline { 2 - 4 } & Female & 94 & $47.7 \%$ \\
\hline \multirow{3}{*}{ Residency } & Rural & 24 & $12.2 \%$ \\
\cline { 2 - 4 } & Urban & 173 & $87.8 \%$ \\
\hline \multirow{3}{*}{ Marital Status } & Single & 163 & $82.7 \%$ \\
\cline { 2 - 4 } & Married & 33 & $16.8 \%$ \\
\cline { 2 - 4 } & Divorced & 1 & $0.5 \%$ \\
\hline \multirow{4}{*}{ College Year } & 1 & 2 & $1 \%$ \\
\cline { 2 - 4 } & 2 & 3 & $1.5 \%$ \\
\cline { 2 - 4 } & 3 & 29 & $14.7 \%$ \\
\cline { 2 - 4 } & 4 & 36 & $18.3 \%$ \\
\cline { 2 - 4 } & 6 & 39 & $19.8 \%$ \\
\cline { 2 - 4 } & Intern & 46 & $23.4 \%$ \\
\hline
\end{tabular}

\section{Table 3}

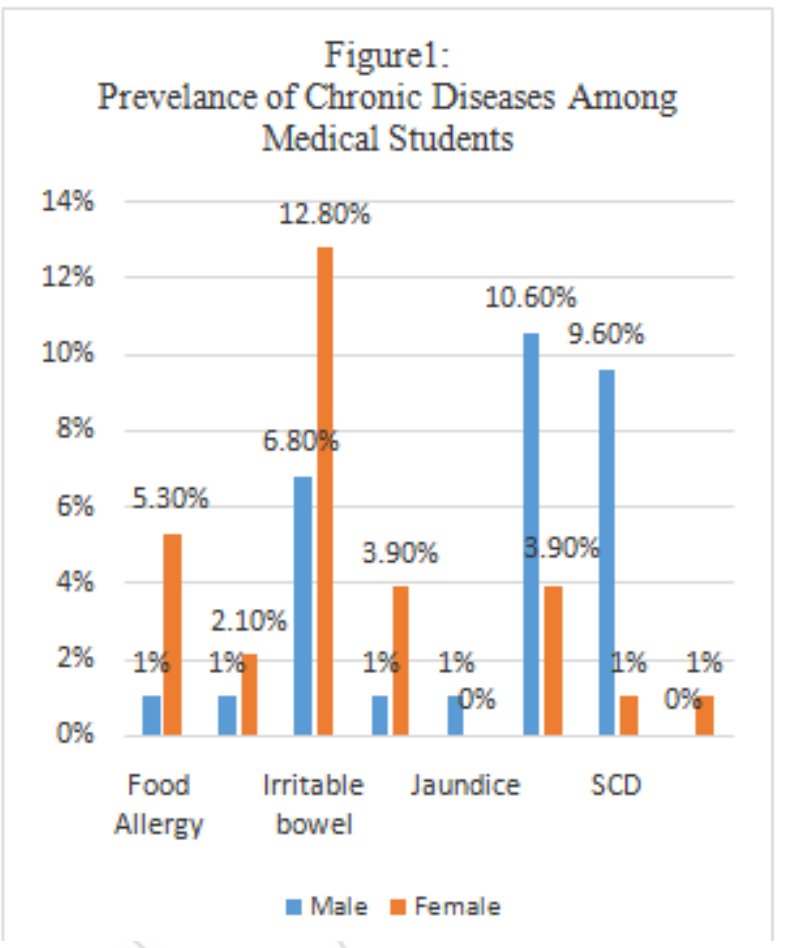

Table 2

Factors leading for college absenteeism among study participants

\begin{tabular}{|c|c|c|}
\hline & & \\
\hline Appointment & 20 & $10.2 \%$ \\
\hline Chronic condition bother you & 18 & $9.1 \%$ \\
\hline Illness: Appointment & 4 & $2 \%$ \\
\hline Illness: Overslept & 6 & $3 \%$ \\
\hline Illness; Overslept; Appointment & 2 & $1 \%$ \\
\hline Overslept & 45 & $22.8 \%$ \\
\hline Overslept; Appointment & 6 & $3 \%$ \\
\hline Total & 197 & $100 \%$ \\
\hline
\end{tabular}

Figure 2

the the effect of chronic diseases on GPA

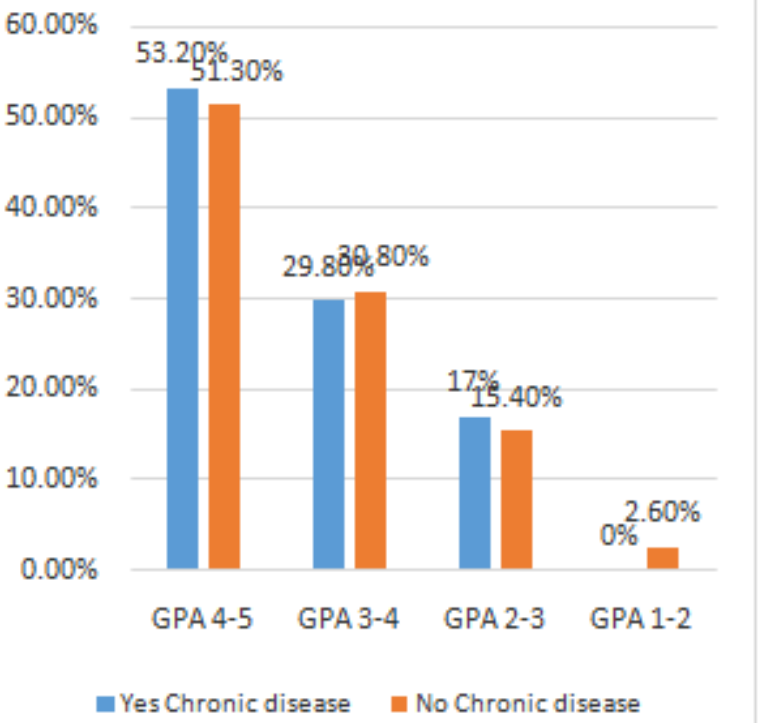




\section{International Journal of Science and Research (IJSR) \\ ISSN (Online): 2319-7064}

Index Copernicus Value (2013): 6.14 | Impact Factor (2015): 6.391

\section{References}

[1] (WHO discussion papers on adolescence). Geneva, Switzerland: WHO World health report 2002: reducing risks, promoting healthy life. Geneva: World Health Organization; 2002 (http: //www.who.int/whr/2002/en/).

[2] Koen Luyckx, Seth J Schwartz, Bart Soenens UGent, Maarten Vansteenkiste UGent and Luc Goossens (2010) Journal Of Counseling and Development. 88(1). p.52-60

[3] Kerr, S., Johnson, V.K., Gans, S.E., Krumrine, J. (2004). Predicting adjustment during the transition to college: Alexithymia, Perceived Stress, and Psychological Symptomes. Journal of College Student Development, 45(6), 593-611.

[4] Stress, coping and suicide ideation in Chinese college students. Zhang $\mathrm{X}^{1}$, Wang H, Xia Y, Liu X, Jung E.J Adolesc. 2012 Jun;35(3): 683-90. doi: 10.1016/j.adolescence.2011.10.003. Epub 2011 Oct 26.

[5] Fennell, P.A., Leitz, P., \&Fantauzzi, A. (2009). Accommodating students affected by chronic illness. (Albany Health Management Associates, Inc.).

[6] Molson, E.S., Hullmann, S.E., Eddington, A.R., \& Mullins, L.L. (2011). Depression, anxiety, and healthrelated quality of life in adolescents and young adults with allergies and asthma. Journal of Asthma \& Allergy Educators, 2(288). doi: 10.1177/2150129711416501.

[7] The cognitive and academic impact of sickle cell disease. Day S ${ }^{1}$, Chismark E.J SchNurs. 2006 Dec;22(6): 330-5.

[8] Maslow, G.R., Haydon, A., McRee, A., Ford, C.A., \& Halpern, C.T. (2011). Growing up with a chronic illness: Social success, educational/vocational distress. Journal of Adolescent Health, 49(2), 206-12.

[9] Physical activity and public health: updated recommendation for adults from the American College of Sports Medicine and the American Heart Association. Haskell WL1, Lee IM, Pate RR, Powell KE, Blair SN, Franklin BA, Macera CA, Heath GW, Thompson PD, Bauman A.

[10] Sawyer, M.G., Reynolds, K.E., Couper, J.J., French, D.J., Kennedy, D., Martin, J. Baghurst, P.A. (2004). Healthrelated quality of life of children and maternity.

[11] Lawless, Casey, "Academic and Mental Health Functioning in College Students with Chronic Medical Conditions" (2013). Syracuse University Honors Program Capstone Projects. Paper 41.http: //surface.syr.edu/honors_capstone/41

[12] FREQUENCY OF IRRITABLE BOWEL SYNDROME IN COLLEGE STUDENTS. JAFRI W, YAKOOB J, JAFRI N, ISLAM M, ALI QM.J Ayub Med Coll ABbotTABAD. 2005 OCT-DeC; 17(4): 9-11.

[13] A Cross Sectional Study of Nutritional Anemia among Medical Students in a Medical College, at Bilaspur, Chhattisgarh (Sachin Pandey, Arun Singh.)Natl J Med Res. 2013; 3(2): 143-146.

[14] Pleis JR, Lethbridge-Çejku M. Summary health statistics for U.S. adults: National health interview survey, 2005. National Center for Health Statistics. Vital Health Stat 10(232). 2006

[15] Wadesango N, Machingambi S: Causes and structural effects of student absenteeism: a case study of three South African Universities. J Soc Sci. 2011, 26 (2): 8997.

[16] Kottasz R: Reasons for student non-attendance at lectures and tutorials: an analysis. InvestigUniv Teach Learn. 2005, 2 (2): 5-16.
[17]ABSENTEEISM AMONG MEDICAL AND HEALTH SCIENCE UNDERGRADUATE STUDENTS AT HAWASSA UNIVERSITY, ETHIOPIA. AUTHORS: ANTENEH ASSEFA DESALEGN $^{\dagger}$, ASRES BERHAN ${ }^{\dagger}$ AND YIFRU BERHAN BMC MEDICAL EDUCATION BMC SERIES OPEN, INCLUSIVE AND TRUSTED201414: 81DOI: 10.1186/1472-6920-14-81.

[18] De Mello MT, LemosVde A, Antunes HK, Bittencourt L, Santos-Silva R, Tufik S: Relationship between physical activity and depression and anxiety symptoms: A population study. J Affect Dis 2013, 149: 241-246.

[19] ASSESSMENT OF PHYSICAL INACTIVITY AND PERCEIVED BARRIERS TO PHYSICAL ACTIVITY AMONG HEALTH COLLEGE STUDENTS, SOUTH-WESTERN SAUDI ARABIA. AwADAlla NJ, ABOELYAZED AE, HASSANEIN MA, KHALIL SN, AFTAB R, GABALlA II, MAHFOUZ AA.EAST MEDITERR HEALTH J. 2014 OCT 20;20(10): 596-604.

[20] CIGARETTE SMOKING AMONG UNIVERSITY STUDENTS IN GREECE: A COMPARISON BETWEEN MEDICAL AND OTHER STUDENTS EVANGELOS C. ALEXOPOULOS, 1 ELENI Jelastopulu, 1 KonSTANTINOS ARONIS, 1 AND DiMITRIS Dougenis2. Environ Health Prev Med. 2010 Mar; 15(2): 115-120. PUBLISHED ONLINE 2009 OCT 3. DOI: 10.1007/s12199-009-0110-0

[21] THE GROWING BURDEN OF CHRONIC DISEASE IN AMERICA. ANDERSON G ${ }^{1}$, HoRVATH J.PubliC HEAlTH REP. 2004 MAY-JUN;119(3): 263-70.

[22] QUALITY OF LIFE AND WELLBEING OF THE ELDERLY IN LEBANESE NURSING HOMES. DOUMIT J ${ }^{1}$, NASSER R.INT J HEALTH CARE QUAL ASSUR. 2010;23(1): 72-93.

[23] IMPACT OF HEALTH EDUCATION ON COMPLIANCE AMONG PATIENTS OF CHRONIC DISEASES IN AL QASSIM, SAUDI ARABIA FAWZYSHARAF.INT J HEALTH SCI (QASSIM). 2010 Nov; 4(2): 139-148.

[24] Sutrees, P. g., Wainwright, N., W., Khaw, K. T., day, N.E. (2003). Functional health status, chronic medical conditions and disorders of mood. British Journal of Psychiatry, 183, 299-303.

[25] Wagena, E. J., Kant, I., Huibers, M., vaAmelsvoort, L., Swaen, G., Wouters, van Schavck. C. (2004).

[26] El-Qudah, J.M., 2008. Food consumption patterns and prevalence of obesity in an adult population in Amman, Jordan. Aust. J. Basic Appl. Sci., 2(4): 1165-1171.

[27] Nasreddine, L., N. Hwalla, A. Sibai, M. Hamze and D. Parent-Massin, 2005. Food consumption patterns in an adult urban population in beirut, lebanon. Pub. Health Nutr., 9(2): 194-203.

[28] Michaud, P.A., Suris, J.C., \& Viner, R. (2007). The adolescent with a chronic condition: Epidemiology, developmental issues and health care provision.

[29] Wolf, L. E. (2001). College students with ADHD and Other Hidden Disabilities. Annals of the New York Academy of Sciences, 93, p. 385-395.

[30] Schneiderman, N. (2004). Psychosocial, behavioral, and biological aspects of chronic diseases. Current Directions in Psychological Science, 13(6), 247-251 